\title{
LEARNER-CENTRED EDUCATION IN INTERNATIONAL PeRspective
}

\author{
Michele Schweisfurth ${ }^{\mathrm{a}}$ \\ University of Glasgow
}

\begin{abstract}
This article provides an overview of Learner-Centred Education (LCE) as a travelling policy and outlines some of the arguments and pathways that have been used to fuel its travel. Despite the rich promises it offers and its proliferation as a global phenomenon and national policy, there is evidence that implementation and changes to classroom practice have proved to be problematic in many contexts. This seems particularly true in developing countries, and the article explores some of the reasons behind these perennial gaps. It concludes by arguing for the importance of both a 'bird's-eye view' and local understandings in researching and operationalising LCE, and suggests ways that the local and the global might be reconciled so that the promise of LCE is not lost in translation.
\end{abstract}

\section{Introduction}

Learner-Centred Education (LCE) is a 'travelling policy' (Ozga \& Jones, 2006) which has been endorsed by international agencies, national governments, and local innovators. Promoters of this pedagogical tradition refer to theories and evidence from cognitive psychology, claiming that all learners can benefit from it in improved processes and outcomes. Beyond the benefits to the individual, however, lies a set of assumptions about learner-centred education as a foundation for the building of democratic citizens and societies, and the development of a skilled population ready for the knowledge economies of the future. These promises have been questioned by critics who doubt that it is appropriate in all cultural and resource contexts, and there is considerable evidence in the global South of perennial problems of implementation (Schweisfurth, 2011).

This article outlines some of these debates. It will consider LCE as a global phenomenon, LCE in lower and middle-income countries, and what a culturally- and contextually-sensitive approach to LCE might entail. It concludes with reflections on the value of an international perspective in the study of travelling policies and global orthodoxies like LCE. Many of the ideas presented here are developed further in an imminently forthcoming book on this subject: Learner-centred Education in International Perspective: whose pedagogy for whose development? (Schweisfurth, 2013). The approach here will be broad-brush comparative rather than exploring in detail particular case studies, although selective international examples will illustrate the overall patterns. This 'bird's-eye view' is valuable for observing travelling policies (Steiner-Khamsi, 2011).

\section{Learner-Centred Education as a Concept, a Narrative, and a Travelling Policy}

Learner-centred education (LCE) has historical roots that extend back to the time of Socrates (400 B.C.) but it was the influence of continental philosophers of the late $19^{\text {th }}$ and early $20^{\text {th }}$ centuries who questioned the nature of childhood and how children should be educated who helped to spread its influence in North America and the UK. Another major influential thinker and writer on the subject in the early $20^{\text {th }}$ century was American philosopher and educationist John Dewey (1916), who linked 'progressive' pedagogy to the development of democratic skills and dispositions in learners. In the more recent past, the Brazilian Paulo Freire (1972) helped to shape the international landscape of

a Correspondence can be directed to: Michele.schweisfurth@glasgow.ac.uk 
adult education in particular with his notion of conscientisation. He linked this to pedagogies for literacy which promoted questioning of the status quo as an antidote to the prevailing 'banking' model of education based on the depositing of knowledge from teacher to student. Also contributing to the rich foundation literature for LCE are writers such as Vygotsky (1978) and Bruner (1966) who have understood learning in a constructivist paradigm - i.e. knowledge as co-constructed by learners and teachers, with teachers playing a social, interpersonal and facilitative rather than whole-class instructive role.

With these varying roots in romantic notions of childhood, visions of a more democratic society through schooling, emancipatory ambitions for oppressed adults, and teachers as facilitators of individual learning, it is not surprising that the concept of LCE is rather loose. If we add to the mix the fact that is has manifestations within many different cultural, political and resource realities, then it becomes even less easy to pin down and define with universal clarity. In many ways, therefore, LCE as a concept is best studied phenomenologically, allowing for different definitions and interpretations across different contexts. However, for the purposes of this article, LCE will be defined as one end of a continuum of pedagogical practices. Compared to, for example, lecturing, drilling or other methods driven by a fixed curriculum and rote learning, LCE: '...gives learners, and demands from them, a relatively high level of active control over the contents and processes of learning. What is learnt, and how, are therefore shaped by learners' needs, capacities and interests' (Schweisfurth, 2013, p.20).

From this apparently simple definition however, flow a number of justificatory narratives which have been used by theorists, policymakers and international agencies in promoting LCE. One of these is the cognitive narrative. Learner control over the content and process of learning is supported by evidence from cognitive psychology (summarised well by Ginnis, 2002) suggesting that this control helps learners to build up from existing knowledge neural connections and meaningful patterns which lead to more effective and sustainable learning. The intrinsic motivation that comes from learning something of significance and importance to them additionally helps to focus students on learning and this engagement is crucial to the process. This narrative also references Vygotsky and Bruner's constructivist understandings of learning. A second narrative, emancipation, echoes Freire and Dewey's emphasis on education's potential both to undermine and serve the freedoms of individuals, and how pedagogy can help learners to develop the knowledge, skills, attitudes and behaviours which over time can transform society. Again, the emphasis on learner control is central, but made more radical with the introduction of the notion of critical pedagogy, in which learners not only have more control over what they learn and the process of learning, but are encouraged to question critically canons of received knowledge and the unequal structures of society which they support. A third narrative has considerable policy relevance and has been invoked in many contexts: the preparation narrative. Knowledge economies which trade in information and services rather than manufactured goods are widely considered the norm in OECD countries and the direction of future development (OECD, 1996). The skills developed through inquiry-based self-regulated learning such as flexibility, critical independent thought and entrepreneurship are believed to support the development and sustaining of an effective knowledge economy.

These are appealing narratives in any context, but in developing countries the promise of their link to various understandings of development gives them particular salience. Evidence (not uncontested but widely-cited) points to the power of education to develop human capital and thereby contribute to economic growth. It is also linked, for example, to improved health outcomes, including in the children of educated mothers (Colclough, 2012). It follows that if learning is more effective, as the cognitive narrative promises from LCE, then these outcomes will be amplified. Some understandings of development place rights, freedoms and democracy at its centre (see Sen, 1999) in line with the emancipatory narrative. And while most higher-income countries are functioning as knowledge economies already, most middle-income countries aspire to this; developing countries 
naturally do not want to be left behind. Education policies in a number of countries, including China, Russia, India and South Africa all reference this narrative.

Given this broad appeal, LCE's status as a travelling policy is not surprising; governments seeking to resolve a range of national concerns from economic growth to democratisation to conflict resolution to modernisation of the labour market will find these narratives attractive. But also key to this status is the role of international organisations that promote LCE within a rights framework or make LCE a part of their definitions of quality education. UN agencies are particularly active in this regard, UNESCO and UNICEF both building LCE into their visions for improved schooling. UNESCO's Associated Schools Project Network, for example, which includes some 8500 schools internationally, promotes the following 'essential dimensions' of quality education:

1. Improving the content of education by making it more relevant and pertinent

2. Enhancing the learning process whereby students are the main actors and teachers the facilitators

3. Developing life skills and competences which enable children and young people to succeed in a fast changing world of challenges and opportunities

4. Emphasising creativity and imagination and well as developing the many talents to be found in each learner

5. Introducing cross-curricular and interdisciplinary approaches as well as team teaching and hence fostering a holistic approach to education

6. Improving the climate of the school

7. Reinforcing democratic principles (UNESCO, 2008, p.7).

There are also examples among individual aid and non-governmental agencies, and networks which combine the efforts of a range of donors, such as the International Network for Education in Emergencies (INEE). The INEE endorses LCE as one of its 'minimum standards' for education in emergency and post-emergency situations:

For people to learn effectively, participatory teaching and learning techniques, including learnercentred methodologies, are essential. Child-centred methods should address the needs of the whole person, teaching skills necessary for survival, individual development, social interaction, and academic study (INEE, 2004, p.54)

So, impetus for moving towards LCE comes from a number of directions, from local, national and global actors and agents. However, despite these almost universal endorsements, LCE has not proved to be a straightforward policy to implement and its global prescriptions have very different local variants. It is in this context that: '...the comparative perspective comes into its own, both as a correction to broad-brush, decontextualised statements, and as a way of triangulating multiple sets of findings to aid in the quest to sift the local from the global' (Schweisfurth, 2013, p.36).

\section{Implementing LCE in New Contexts: Lower and Middle Income Countries}

As a globally travelling policy and practice, prescriptions and innovations regarding LCE are often found in contexts where it is culturally new and where the realities of educational governance and resources for schools have not historically accommodated it. In a recent analysis of the research on LCE implementation reported in a (or perhaps 'the') international journal on education and development (Schweisfurth, 2011), it was evident that '...the history of the implementation of LCE in different contexts is riddled with stories of failures grand and small' (Schweisfurth, 2011, p.425). Across a wide range of developing country contexts, the reports of 'tissue rejection' (Harley et al., 2000) as teachers and learners struggle to make the 'paradigm shift' (Nakabugo and Siebörger, 2001; Tabulawa, 2003) far outnumbered the stories of successful transitions from the pedagogies in place towards LCE. 
What do these pedagogies in place look like? In a survey of 102 video-recorded lessons in Kenya, as a baseline data set to an LCE-oriented intervention, Hardman et al. (2009) describe pedagogical norms which are fairly typical of much of Sub-Saharan Africa and other parts of the developing world: lessons dominated by lecturing, with occasional question-and-answer, copying, and individual written exercises; mainly closed questions being asked (98\%); pupil questioning rare; boys twice as likely to be asked a question by the teacher as girls; more than $33 \%$ choral answers; only $3 \%$ of lessons including pair or group work; and a traditional, desks-in-rows classroom layout in $96 \%$ of lessons. If there is truth to the benefits of LCE as laid out in the narratives above, then most learners in poorer parts of the world are not experiencing it and introducing LCE through policy reform does not seem readily able to change that.

Policy sociology notes that whatever the policy, the predicted and wished-for straight line from policy intention to classroom practice is often problematic. I will here explore four broad areas which research has indicated can be barriers to effective implementation of LCE specifically. Firstly, the policy process itself can be a barrier, as policy messages can be difficult for teachers to understand, can be contradictory, or the process may not be supported in different parts of the system (teacher education and inspection, for example, can work against LCE if they are not 'on message'). A classic and recurrent policy contradiction is to promote LCE pedagogy in situations where high-stakes examinations which test fixed knowledge drive teacher, student and parent motivation. As a student, if your future education and career depend on examination results, the open-ended exploration of content not likely to be tested will seem like a luxury, and teachers will teach to examinations to meet students' needs and to protect their own reputations. This has been shown to be the case in a wide range of contexts where policy has pointed both to LCE and to tight assessment frameworks, South Africa and China being prevalent examples. Furthermore, in contexts of fragility, the policy process is complicated by a range of factors from poor infrastructure to corruption to prioritisation of survival needs, all of which make the reach of government initiatives problematic.

Secondly, material resource shortages are often cited by teachers as a major issue in terms of their ability to meet policy demands or other encouragements in LCE directions. They note the physical environment, class size and teaching materials as impediments to the adoption of LCE pedagogical approaches. While not belittling such concerns, it is noteworthy that in placing these at the forefront of their barriers, teachers place the problem outside of themselves; however, they also stress the importance of recognition in and appreciation in motivating them to try new pedagogical approaches (VSO, 2002). Human resources have been shown to be a significant part of the equation and of course motivation is an important dimension of this. Teacher motivation is problematic across much of the developing world, where working conditions and salaries do not make teaching a first choice profession, and where respect from the government, the press and local communities cannot be taken for granted. In the poorest countries, and in the poorest and most remote parts of middle and low income countries, teachers are often untrained or undereducated. Many teachers are expected to work in a language of instruction - usually a colonial language and usually English - in which they are not comfortably fluent. This has been shown to make them more cautious in classroom dialogue and they tend to ask closed questions and use drills as strategies for ensuring that the discussion does not slip beyond their comprehension or comfort zone (Brock-Utne \& Holmarsdottier, 2004 on Tanzania and South Africa). As an additional important dimension of the human resource base, teacher professional identity is a highly context-specific phenomenon, but in many parts of the developing world the reflective and autonomous practitioner embedded in developed forms of LCE is not nurtured.

Culture shapes all of these phenomena, and interacts profoundly with teacher-learner relationships and classroom behavioural norms. Two of Hofstede's (2003) cultural continua create a helpful language here. Some cultures have greater 'power distance' between those with less and more power in a society, such as teachers and students: it is alien in such countries to have a close and familiar relationship with a teacher or to question his or her wisdom. In collectivist cultures, 
the integration of people into a strong, cohesive in-group is the norm, and so the individualising of curricula rather than a focus on the class collective may seem inappropriate. Both of these have major implications for LCE as it is widely conceived. Sternberg (2007) notes that one of the universal lessons of learning is that being taught in culturally-appropriate ways raises achievement, raising an interesting conundrum for those seeking to introduce LCE into high power distance and collectivist societies.

There are of course many rich contextual details which illustrate, nuance or correct these generalisations, and the book (Schweisfurth, 2013) develops five case studies which explore these. There are also positive stories of LCE implementation, usually where there has been joined-up thinking across the whole education sector, from pre-service training through school management through supervision, inspection and support regimes through in-service professional development. These all demand, however, a policy and practice context which is coherent in itself, well-resourced on the human front, and in which there is a critical mass of actors already deeply familiar with the demands, joys and practices of LCE, rather than rhetorical prescriptions. They also raise substantial questions about the extent to which LCE as moves in its travelling manifestations is a desirable and feasible policy and practice in all contexts, and some writers have concluded that it is not appropriate for some environments (e.g. Guthrie, 2011) where investment in improving tried-and-tested formal pedagogies offers a more promising return on investment.

\section{Towards Contextualised Learner-Centred Pedagogies}

There are a number of ways of conceptualising this problematic uptake of LCE in developing country contexts.

One way, as Guthrie has done, is to argue that LCE is fundamentally unsuited culturally and in terms of the resource context in many parts of the developing world. However, there are a number of pieces of evidence and rights-based arguments that put question marks against that conclusion. We do see success stories, and teacher and pupil enthusiasm for LCE when the implementation is well-managed (e.g. Khamis \& Sammons, 2007; Hardman et al., 2009). Human rights arguments rise above these questions of evidence; if LCE is the approach that respects learners' rights, as UNESCO and other agencies would have it, then the effort to implement it must go on. Context matters, but context isn't everything.

Another way of thinking about the problem is to see it as a problem of governance and management. If the aim is to introduce LCE, then the best way forward is to try to fix the broken cycles of implementation which are proven barriers, whether it is the policy process, the support for teachers at each stage of their professional development, or the contradictions such as high-stakes examinations which work against LCE. This is a big demand in contexts where resources and capacity are stretched, and where there are very few people working within the implementation structures who have personal experience of LCE.

I would argue that the only way through the impasse is to think of LCE as a series of continua, rather than seeing it as a single absolute that has only one international configuration. This means that some aspects of the pedagogical practice can be emphasised more strongly than others, to fit the cultural context. So, in collectivist societies, it may be a case of a communal understanding of the needs of a class rather than the needs of each individual in it. This perspective is not uniquely needed in developing countries and historical studies have pointed to different interpretations of LCE across time and space in the US and the UK (Brehony, 2001; Chung \& Walsh, 2001; Cunningham, 2001). They have also pointed to more rhetoric than consistent reality even during times when learner-centredness is in vogue both in terms of policy and teacher discourse, such as the 'Plowden Era' in the 60s and 70s in the UK (Alexander, 2000). So it seems only reasonable to expect that in developing countries where the challenges are deeper and the cultural roots of LCE are less resonant, there will be local variants in terms of the degree and nature of LCE uptake. There are a number 
of authors who have called for contextualised understandings of LCE, and for the de-polarisation of LCE pedagogy from those approaches which have traditionally been seen as its opposites, in order to create a more inclusive LCE which reflects and respects local realities (e.g. Croft, 2002; Barrett, 2007; Alexander 2008; Sriprakash, 2009; Vavrus, 2009).

The risk with this approach is that anyone can call anything LCE, without due attention to its potential for cognitive development, respect for rights and goals of emancipation, and possibilities for future-oriented skills development. The way forward might be to agree a set of minimum standards which must be upheld within contexts where there is a consensus on the need for LCE. In the book (Schweisfurth, 2013, p.146) I set out such a set of minimum standards for LCE, to provoke further discussion on what is local and what must be seen as globally applicable. All of these need to work together to meet LCE minimum standards in this vision of this pedagogy. The seven standards set out are:

1. Lessons are engaging to pupils, motivating them to learn (bearing in mind that different approaches might work in different contexts).

2. Atmosphere and conduct reflect mutual respect between teachers and pupils. Conduct such as punishment and the nature of relationships do not violate rights (bearing in mind that relationships might still be relatively formal and distant).

3. Learning challenges build on learners' existing knowledge (bearing in mind that this existing knowledge might be seen collectively rather than individualistically).

4. Dialogue (not only transmission) is used in teaching and learning (bearing in mind that the tone of dialogue and who it is between may vary).

5. Curriculum is relevant to learners' lives and perceived future needs, in a language accessible to them (mother tongue except where practically impossible) (bearing in mind that there will be tensions between global, national and local understandings of relevance).

6. Curriculum is based on skills and attitude outcomes as well as content. These should include skills of critical and creative thinking (bearing in mind that culture-based communication conventions are likely to make the 'flavour' of this very different in different places).

7. Assessment follows up these principles by testing skills and by allowing for individual differences. It is not purely content-driven or success based only on rote learning (bearing in mind that the demand for common examinations is unlikely to be overcome).

In conclusion, I would look towards a more hopeful and holistic version of LCE which builds on existing pedagogical practices rather than attempting (fruitlessly) to usurp them. But the learner needs contextualising not just in their own classroom but in wider national development needs and in an increasingly important global context. In this, a globalised, bird's-eye view is certainly of value but it needs to be offset with local understandings.

\section{References}

Alexander, R. J. (2000). Culture and Pedagogy: International Comparisons in Primary Education. Oxford: Blackwell.

Alexander, R. J. (2008). Education for All, The Quality Imperative and the Problem of Pedagogy. Brighton: Consortium for Research on Educational Access, Transitions and Equity.

Barrett, A. (2007). Beyond the polarisation of pedagogy: models of classroom practice in Tanzanian primary school. Comparative Education, 43(2), 273-294.

Brehony, K. (2001). From the particular to the general, the continuous to the discontinuous: progressive education revisited. History of Education: Journal of the History of Education Society, 30(5), 413-432.

Brock-Utne, B. and Holmarsdottir, H. (2004). Language policies and practices in Tanzania and South Africa: problems and challenges. International Journal of Educational Development, 24, 67-83.

Bruner, J. (1966) Toward a Theory of Instruction. London: Harvard University Press. 
Chung, S. and Walsh, D. (2001). Unpacking childcentredness: a history of meanings. Journal of Curriculum Studies, 32(2), 215-234.

Colclough, C. (2012). Education, poverty and development - mapping their interconnections. Comparative Education, 48(2), 135-148.

Croft, A. (2002). Singing under a tree: does oral cultural help lower primary teachers to be learnercentred? International Journal of Educational Development, 22(3-4), 321-337.

Cunningham, P. (2001). Innovators, networks and structures: towards a prosopography of progressivism. History of Education: Journal of the History of Education Society, 30(5), 433-451.

Dewey, J. (1916). Democracy and Education. New York: MacMillan.

Freire, P. (1972). Pedagogy of the Oppressed. London: Penguin.

Ginnis, P. (2002). The Teacher's Toolkit. Carmarthen: Crown House Publishing.

Guthrie, G. (2011). The Progressive Fallacy in Developing Countries: In favour of formalism. New York: Springer

Hardman, F., Abd-Kadir, J., Agg, C., Migwi, J., Ndambuku, J. and Smith, F. (2009). Changing pedagogical practice in Kenyan primary schools: the impact of school-based training. Comparative Education, 45(1), 65-86.

Harley, K., Barasa, F., Bertram, C., Mattson, E. and Pillay, S. (2000). 'The real and the ideal': teacher roles and competences in South African policy and practice. International Journal of Educational Development, 20, 287-304.

Hofstede, G. (2003). Culture's Consequences: Comparing Values, Behaviours, Institutions, and Organisations Across Nations ( $2^{\text {nd }}$ ed.). London: Sage (see also website at http:// www.geerthofstede.com) [accessed August 2, 2011].

INEE (2004). Inter-Agency Network for Education in Emergencies: Minimum standards for education in emergencies, chronic crises and early reconstruction. Available at http://www.ineesite.org. [accessed 21 February 2013].

Khamis, A., Sammons, P. (2007). Investigating educational change: The Aga Khan University Institute for Educational Development teacher education for school improvement model. International Journal of Educational Development, 27, 572-580.

Nakabugo, M. G. and Sieborger, R. (2001). Curriculum reform and teaching in South Africa: making a 'paradigm shift'? International Journal of Educational Development, 21, 53-60.

OECD (1996). The Knowledge-based Economy. (available at http://www.oecd. org/ dataoecd/51/8/1913021.pdf.) [accessed March 8, 2011].

Ozga, J. and Jones, R. (2006). Travelling and embedded policy: the case of knowledge transfer. Journal of Education Policy, 21(1), 1-17.

Schweisfurth, M. (2011). Learner-centred education in developing country contexts: from solution to problem? International Journal of Educational Development, 31, 425-432.

Schweisfurth, M. (2013). Learner-centred education in international perspective: whose pedagogy for whose development? London: Routledge.

Sen, A. (1999). Development as Freedom. Oxford: Oxford University Press.

Sriprakash, A. (2009). 'Joyful learning' in rural Indian primary schools: an analysis of social control in the context of child-centred discourses. Compare, 39(5), 629-642.

Steiner-Khamsi, G. (2011). The Relation between First-order Policy Change, Policy Cycles, and Policyscapes. Paper presented at the Comparative and International Education Society Conference, Montreal, 4 May 2011.

Sternberg, R. J. (2007). Culture, Instruction and Assessment. Comparative Education, 43 (1), 5-22.

Tabulawa, R. (2009). Education reform in Botswana: reflections on policy contradictions and paradoxes. Comparative Education, 45(1), 87-107.

UNESCO (2008) First Collection of Good Practices for Quality Education. (available at http://unesdoc. unesco.org/images/0016/001627/162766e.pdf) [accessed March 29,2011].

VSO (2002). What Makes Teachers Tick? A Policy Research Report on Teacher Motivation in Developing Countries. London: VSO. 
Vavrus, F. (2009). The cultural politics of constructivist pedagogies: teacher education reform in the United Republic of Tanzania. International Journal of Educational Development, 29, 303-311. Vygotsky, L. (1978). Mind in Society: The Development of Higher Psychological Processes. Cambridge: Harvard University Press. 